\title{
A Study on the Father Image in Chinese Film and Television
}

\author{
Fangyi $\mathrm{Xu}^{1}$ \\ ${ }^{1}$ School of Journalism and Communication, Tsinghua University, Beijing, China \\ Correspondence: Fangyi Xu, Weixiu Garden Building 16-308, Peking University, Haidian District, Beijing \\ 100871, China. Tel: 86-138-1079-6315. E-mail: xfyacademic@163.com
}

Received: January 28, 2021

Accepted: February 3, 2021

Online Published: February 28, 2021

doi:10.5539/ass.v17n3p31

URL: https://doi.org/10.5539/ass.v17n3p31

\begin{abstract}
The father image in Chinese film and TV shows is often absent or lacks power. This is a new phenomenon presented by fathers in social relations, family relations and self-identity and reflects the implicit identity anxiety behind the father image in the new pattern of middle-class families. The father image in film and TV shows is no longer a symbol of power and authority of the traditional patriarchy but a deconstruction from the loss of discourse to disintegration, not only reflecting the loss of discourse of individuals' rights but also presenting a certain metaphor of the era. Fathers recovering from their image collapse requires a new sublimation image so that their power representation and self-worth can be renewed.
\end{abstract}

Keywords: Chinese film and television, family ethics, father image, patriarchy

\section{The Problem: The Father Image in Chinese Film and TV Dramas Is Generally Weak and Aphasic}

The father image in China's contemporary local film and TV dramas is often powerless, lacks discourse, and highlights absence. This phenomenon is present not only because the traditional era symbolized by fathers has diminished while a new era represented by the next generation has predominated but also because an internal force has disrupted the process of inheritance and the continuation of the father image. Although their authority was abandoned in the new era, fathers are still present as "Father" in the family and society, but they are no longer able to find their place. This seems to be merely the anxiety of patriarchy but is actually the suspicion of all of society regarding the incarnation of bygone "power." Why is the presentation of fathers, who have always represented power and authority, repeatedly been diminished in film and TV dramas while their values, social relations, and behavior motives are all clearly contradictory?

\subsection{Does Absence and Powerlessness Prove the Loss of Power of Fathers?}

Why does the father image in Chinese film and TV dramas often highlight the loss of discourse and collapse? How and by whom is fathers' power weakened? Why do fathers who seem powerless present a state of inner conflict? Does the collapse of the father image imply changes in the relations within the family in contemporary society? Is it a cultural metaphor?

Although contemporary society is still under the rein of patriarchy, the father image in film and TV dramas has been constantly weakening and diminishing. The rise of feminism and the tide of rationalism have prompted patriarchy to be reevaluated. While it is politically correct to discuss women's rights and power, the discussion of the power of fathers is not encouraged. However, the power of fathers does not equal patriarchy; in the equality of human rights, all parties, including strong and independent women and the next generation with freedom of thought, have gradually become strong. Correspondingly, the power of fathers has weakened. If the power of fathers is not properly shaped, the layout of equality will collapse, creating a blind spot and even a black hole, leading to the loss of the new equilibrium. The power of fathers represents the passing of the old era, in which it is impossible to innovate and reform. Many contemporary film and TV dramas focus on the image of a powerless father and express hidden worries of modern society by deconstructing the father image.

What does a father's absence mean? With the social changes accompanying the outgoing era and the incoming era, it is necessary to reconsider the new expressions of patriarchy in film and TV dramas in the context of modernity. What are the patterns, features and cultural implications of the metaphor of the father image, including themes, content, stereotypes, values and other elements, at the characterization and narrative levels? 


\subsection{How Is the Father Image Re-established and Expected in Film and TV Dramas?}

The powerlessness and loss of discourse of the father image show that the narrative of fathers in contemporary film and TV dramas is vague in the sense of traditional Chinese culture; furthermore, the character setting is often repetitive and passive, and the representation of patriarchy in the new era is pessimistic and disconnected from values. The narrative of the father image and the story have failed to garner support from a complete set of values as well as narrative aesthetics. Does the father image have to collapse? Can the father image be reborn? In this image rebuilding process, what sacrifices do fathers have to make? At what price? Does the reconstruction of the father image conflict with the rise of feminism? Can a new father image reconcile and coexist with the rise of the next generation? What image of the father is worth looking forward to and ideal? These are problems in contemporary film and TV dramas that urgently need to be solved.

Can an outlook of the future be portrayed in film and TV dramas in the new era? What father image does film and TV dramas need to portray in the new era? The father image should be reconstructed from the fragmented, passive, and torn state, be held in high regard, uphold the harmony of traditional Chinese culture, and tolerate the values and spirit of the new era as well as the freedom and independence of the next generation, while taking into account the changes in the family and society after the rise of feminism and incorporating the philosophical thoughts of modernity with the communication theories and values of the new era to create a new father image and cultural image.

By "using any method necessary to reconstruct the new father image," i.e., to examine the construction of the father image with fathers as independent individuals from the perspective of the internal father image, the father image become a "present tense" and "future tense" topic. There is not a fixed perspective that uses "past tense" to indicate that the era represented by father does not exist but, rather, a perspective of the present and future based on equal rights and the development of modern society without antagonizing the father image and based on exploring the possibility of developing and innovating the father image in the new era.

\section{Deconstruction on the Father Image: Multiparty Conflicts and Complex Narratives}

\subsection{The Complex Adversarial Relations in Multiple Themes and Types: Absence and Powerlessness}

The father image has always had a distinctive cultural representation and age characteristics in Chinese film and TV dramas. In human patriarchal society, the image of the father represents the authority of history and is a symbol of power in traditional culture. The tradition represented by the father image in Chinese film and TV dramas has always been ingrained with the characteristics of the times, whose intentional change is often a metaphor of the era. In early Chinese films, due to the cultural aspirations to rejuvenate the country and the nation, the image of the father has quietly declined from the status of the monarch of the family. "Reconstructing the 'family' image and the 'fatherhood' ideal became an important task in China's early films. This important task, being incorporated with the booming mission of anti-imperialism and anti-feudalism of the times, acquired a more profound ideologic orientation. Precisely because of this, the reconstruction of the 'family' image and the 'fatherhood' ideal in early Chinese films adopted a very unique alternative strategy: in the dominant narrative motive of films, the fatherhood image, once occupying an important position, was completely replaced by the image of the next generation, which for the first time became the key discourse topic. To accomplish 'parent-child role-switching,' the image of the family, which had been indispensable, was intentionally or unintentionally portrayed as absent, abandoned by the next generation as a negative factor." $(\mathrm{Li}, 2002)$

After entering the age of peace, with productivity improvements and class differentiation, the father identity no longer required fathers to struggle and fight on behalf of their family, but fathers faced a return from the outside to the inside. "The destruction of the two world wars and the subsequent Vietnam War was combined with the aggressiveness of fathers, and the perception of this relationship led to a steady increase in the number of non-aggressive fathers" (Zoja, 2015, p. 4) . Fathers had to abide by social rules in social relations, and after returning to their families, there was another set of family rules. Their dual identities led to conflict, causing their self-identity to collapse. Zhao Jia called fathers' internal and external conflicts a "father's paradox" (Zoja, 2015, p. 7). As Chinese films develop into the contemporary era, in their return, fathers' image is not only non-aggressive but also mild and contradictory. Scholars have categorized the father image in contemporary Chinese films into "authoritative fathers, ordinary fathers and traditional fathers" (Yu, 2009). "Although fathers in some films make people feel depressed or awe-inspired, the vast majority of fathers are peaceful, gentle and even meek and humble: it is already become very difficult for fathers to rebuild their authority, and the decline in patriarchy is still an unstoppable trend. Most importantly, the simultaneous appearance of multiple images of fathers means that contemporary films are increasingly becoming a space where different cultures, values, and powers compromise and compete" (Yu, 2009). 
The image of fathers has also collapsed with their "absence." While the old belief system has collapsed, the new belief system has not yet been established. In previous film and TV dramas, the father's character set, lines, body movements, etc., have certain stereotypes. For example, in the sitcom "I Love My Family" (1993), the father character represents the old tradition: holding a water bottle in hand, speaking a tirade of clichés, and often being rejected by children as pedantic. That empty rhetoric and those clichés fully demonstrate the father's nostalgia for past eras and confusion about new ideas caused by interpreting those ideas with the old belief system. Therefore, in the loss caused by the collapse of the old belief system, father characters have not established a new belief system while exhibiting considerable discomfort searching for new system because they traditionally believe that they always have to find and inherit some meaning; otherwise, they cannot exist as a father that represents authority. Accordingly, their daily status shows two extreme trends: complete loss of discourse or talking incessantly. In "Feng Shui" (2012), Ma Xuewu, the father, committed suicide, making it impossible for his wife and son to communicate with him; in the TV drama "All Is well" (2019), Su Daqiang, the father, after losing control of his wife, was aggressive toward his children and always made things difficult for them. The images of these fathers are all in a stalemate, i.e., neither being able to maintain the value system they adhered to nor being able to find their place in new times.

The father's "absence" in familial involvement is a new structure of family ethics in Chinese films. Not only have fathers continued the traditional "monopolizing affairs outside of the house," but they also return to the family, participate in family affairs, and assume family responsibilities. Therefore, they are capable of handling affairs outside of the house while establishing an image of a majestic and gentle father at home, which has become the expectations of middle-class families for their fathers: the children expect this, the mother expects this, and the father himself expects this, too. Only such a "dually powerful" father image can satisfy fathers' psychological self-identity. However, in reality, the father image is often "dually powerless;" i.e., they lose the ability to handle affairs outside the house and fail to gain communication and reconciliation abilities inside the house. In all types of film and TV dramas with various contents and themes under different worldviews, the father characters, when listed one by one, have vastly different social identities and values, but the father image is almost always passive and aphasic.

Overall, the father image highlights a kind of "powerlessness." He inherits the imagination of authority in the cultural tradition while striving to adapt to the new father identity as an ordinary person after the rise of equal rights of men and women in the new era. In the depowering process, the father exposes his "otherness" identity so that his power is useless and desires cannot be satisfied, and his pain is implicit and heart struggles with conflict, a metaphor for the pain of the times. This is seen in with Lu Yanshi, the father in "Coming home" (2014); Lu, after experiencing the shock of the Cultural Revolution, lags behind the tide of history and thus uproots from the family as well as from history. The father represents the bygone era, and after the advent of the new era, everything has changed, and the old era is abandoned. At this time, the father feels that his rights and abilities are endangered.

In "Sheep Without a Shepherd" (2019), the father is particularly "dually powerless." Li Weijie, the father, an immigrant, runs a small business to support the family, and his powerlessness in the outside world has denied him the legitimacy of being respected as a father, with substantial father-daughter conflict. Li does not give up on family relations exerts effort for the family; his effort is recognized and appreciated by his younger daughter, but his eldest adolescent daughter, who has Oedipus complex, does not pay attention to her father. The family's economic and class situations resulting from the father's small business has caused the eldest daughter to experience many difficult social scenarios that she cannot overcome by herself; she blames her problems on her father's incompetence. Questioning her father's strength and witnessing her father's incompetence are extremely troubling for the daughter. As a result, she is frustrated and struggling and has no one to use for support.

These films and TV shows span and cover a variety of film and TV genres, themes and content, in which, to resist absence and powerlessness, the fathers choose to transcend ethics and undertake self-improvement processes based on having authority and being a role model. Those fathers who commit crimes because of needing to overcome challenges are a microcosm of an era in which males are unable to be self-sufficient and thus lack self-identity. Themes related to family ethics have increased in number, depicting a wide scope of family relations with realistic themes and narratives of intense conflict and ordinary people telling stories that make the audience feel sympathetic and helpless. Fathers' profound sense of powerlessness has caused them to passively disappear from the family's power center, become silent and lose their discourse, which in turn transform into internal anxiety and conflict. In extreme cases, they choose a path of crime and self-destruction that transcends ethics. Cowardly fathers are unable to resist temptation while tenacious fathers take action to resist temptation, trying to prove their worth. This forms a rather extreme genre, i.e., the crime theme. In some 
crime films centered on family ethics, we can see the father's struggle. These crime-themed films show a unique type of anxiety with sharp narrative conflicts. Unlike American crime films or Korean crime films that contain deep self-criticism and self-reflection of capitalist society, China's crime films do not attribute "original sin" to evil or completely lack the concept of "original sin;" instead, they originate from the helpless struggle derived from complying with Confucianism, the local Chinese culture, in which the characters are good-willed, kind and even cowardly, thus not causing any trouble. The "original sin" incidents in which such characters are involved are usually due to helplessness and self-contradiction caused by the inability to reach or cooperate with basic etiquettes and beliefs; therefore, they get salvation by destroying first and then assessing the situation.

\subsection{Relationship Level: Isolation and Resistance in Fathers' Conflicts with the Next Generation}

The character setting and relationship of the father image in contemporary film and TV dramas show distinct anti-traditional and anti-classical characteristics. In terms of character setting, the father has broken the definite symbol representing authority but has turned into a seeker who searches for the meaning of himself, starting from uncertainty. At the level of character relationships, important conflicts caused by the father doubting his identity and purpose stem from family relations. In his interactions with the next generation, the younger generation keeps exerting pressure on the father, causing him great anxiety. The seeker identity of the father image turns fathers into "others," who search for the meaning of existence and achieve self-identity by experiencing their own growth.

The motivation for fathers to seek self-breakthroughs comes from the conflict between the characters and the next generation. The relationship between the father and the family becomes the narrative's driving force, and the game and change in the relationship between the father and children become important narrative elements of exhibiting the father image. The narrative of the new era is often anti-traditional and tears apart modern enlightenment values. The next generation can display anxiety regarding the bygone era represented by their fathers because their beliefs has not been established. This is slightly different in the relationship between father and son and that between father and daughter. The image of sons represents the generation of confusion, nothingness and negation, being unable to establish a new belief system, while that of daughters represent the use of ethics to derive a new belief system, showing sympathy and compassion while replacing reason with emotion because they feel that their fathers are useless but full of sympathy and compassion. In "The Wandering Earth" (2019), the son chooses to not follow his father's footsteps and gradually forms his own values during his solitary adventure, reconciling with his father at the time of his death. In the animated film "Ne Zha" (2019), relative to the mother who often expresses her love to the child, Ne Zha's father rarely expresses himself. Facing the fate of the "demon pill," Nezha, the son, has given up on himself and since led an extremely confused and decadent life until he finally realizes that "I am the master of my fate" and chooses to fight. He also realizes that his father has chosen to sacrifice his own life for his son's life and his son's happiness as well. In other words, facing an aphasic father, the son's reaction to his father also represents a loss of discourse before establishing his own value system. In the TV drama "All Is Well," Su Mingyu, the daughter, humors her father's unreasonable behaviors and is sympathetic to him while feeling helpless, giving her an opportunity to reconcile with her father. The emotional explosion between father and daughter in the final scene enables the daughter to communicate and reconcile with her father.

Children are very sensitive to their father's absence and powerlessness but must be silent about it because they cannot challenge authority by speaking out that their father is unqualified, giving rise to great anxiety. This pressure gradually increases the gap between fathers and children. "Children want their father to be strong and a victor. If a father is a victor, a good man, just and compassionate, then it cannot be better. But more importantly, the father usually represents the image of a man who knows how to triumph and whether to put kindness in a secondary position. Our tradition has often held that a father who behaves justly but fails to succeed in the outside world is far lesser than those who are unjust but triumphant... The father favored by our tradition is the man who does not just take a risk in adopting poor ethical standards but attributes importance to power while being inextricably linked with the limited emotional life." (Zoja, 2015) Witnessing their father or mother being bullied and insulted will have an intense psychological impact on children because in their minds, their parents are strong. When this image of their parent's strength is destroyed, an impact of this magnitude cannot be tolerated by children. This is especially true in the case of a father's humiliation because in traditional culture, in terms of power, the father has more power than the mother, and the mother has more power than the children; therefore, children have a greater expectation regarding the strength of their father. When this expectation cannot be met, children experience great anxiety and pain. Freud's psychoanalytic theory was deeply influenced by his own father, and the patricide psychology in the theory is a complex mentality that contains both jealousy and overtaking. In "Sheep Without a Shepherd," the eldest daughter cannot see her father eye to eye. In "Detective 
Chinatown," the daughter wants her father to die. Relative to the anxiety that the father is unable to change the facts, the children are even more hopeless and thus under greater stress, and this stress is apparent to the father, making him aware that he must work harder to win respect and recognition.

A father's disappointment, on the one hand, originates from an imbalance in self-power and, on the other hand, stems from the inability to look directly in the eyes of the child that has been hurt, mirroring the collapse of father's self-identity. The father in "Detective Chinatown" choses to commit suicide so that he can forever escape the complicated father-daughter relationship. In "Sheep Without a Shepherd," after finding a mobile phone containing a video of his daughter's assault, the father must find inner strength to delete the video. When he found the video, he was so agonized that he immediately looked away. He had to verify the content, but he could also not bear to watch the content. The scene was shot when the father was sitting in a car, which is a confined space. The scene was quiet, and the performance was emotional, making the scene suffocating to viewers and thus having a strong dramatic impact. These scenes exhibit psychological factors: faced with his child's trauma, the father failed to protect his daughter, nor could he solve her issues after the attack. Therefore, in response to his daughter's trauma, he could only punitively inflict self-damage while reinforcing to himself that he is powerless. The absence of a father deeply hurts his family relations while fragmenting his relationship with society. In the process, his loss of discourse gradually diminishes his power, and in times of crisis, his power, due to his precarious position, collapses quickly.

In other words, it is the substantial resistance generated by the power of children that causes dilemmas and mental anguish for fathers, ultimately breaking through barriers and regaining his authority image as father. Fathers face tremendous difficulties and even wallow in a quagmire of violating ethics, as in the typical examples depicted in "Sheep Without a Shepherd" and "Detective Chinatown" (2015). The fathers in these films are "the image of the father with guilt," whose anxiety comes from the "inability to reach" generated by the power relations within the family itself. They did not cause any trouble and strive to protect their wives and children, but social reality and family conflicts forced them to resort to defiant behaviors to deal with their current situation. When reasonable and legal actions cannot achieve their goal, they resort to more extreme means to meet their inner desires, even if they violate basic ethical regulations, exhibiting helplessness and irony in their realistic situation. These films focus essentially on the general anxiety associated with the mundane lives of middle-class families, in which the most irreconcilable situations occur at the level of family ethics. In other words, crimes are committed for the ties of family affection because family affection is based on a patriarchal image that needs to be proved and is worthy of self-destruction in extreme cases. However, anxiety is a chronic means of eroding the middle-class, not an externalized, explicit, real-time conflict; however, its force is not sufficient to disrupt the balance in the world, a portrayal often sought by commercial film. Therefore, many crime-themed films set up certain extreme scenarios, in which anxiety, an "egg" that can be crushed by a single blow, is forcefully and accurately thrown on the "cornerstone" of ethics, morality and psychological desires; the "egg" hits the stone and leaves behind a scene in ruins. Then, an ordinary person, both mentally and physically battered, becomes a hero, cleaning up the mess by committing a crime. Through this kind of destruction, the identity of the ordinary person through his/her spiritual values, including kindness, integrity, and credibility, as well as responsibility and love for the family, is repaired.

\subsection{Complex Narrative: The Father's Self-struggle and Downfall}

The way to show that a father is torn apart by two parties is to shape an extreme situation through narrative aesthetics and externalize a subtle and obscure psychological conflict that deeply affects the character. If the direct struggle against the external environment is a one-dimensional story, with a simple and direct focus, of the growth of a hero, then facing self-struggles and acknowledging one's own inability are actually limiting but more complicated in terms of audiovisual externalization and exactly the artistic expression space of film. In "Sheep Without a Shepherd," the father, to uphold the ethical principles that he has always insisted on, reduces or exempts the rent for a renter who is having difficulties; however, this means that the family's income is reduced accordingly, which is in contrast to his self-expectations as a father that he will provide a good life for his family. Therefore, from the very beginning of the story, the father experiences intense internal conflict.

The story of the father is usually orientated toward the father's loss of ability and discourse. In contrast, the storyline of children points to freedom, equality, independence and strength. Therefore, if the goal of the father's story is to regain an equilibrium in family relations, the father is faced with two extremes that are slowly moving away from each other. Therefore, a mundane life with frequent small conflicts that are difficult to reconcile ultimately accumulate into large conflicts that cause mental fatigue that cannot be resolved overnight. All parties surrounding this conflict are passive, tired, and evasive; therefore, a resolution is as easy as beating monsters. The story arc (Note 1) of the father exhibits passive growth because the self-defense and family-defense 
limitations that he wants to break through prevent his growth. In other words, he is "passively" attacking a "passive" castle, just like "a cotton ball hitting another cotton ball": no matter how much effort has been exerted, there is little effect and even a counterproductive effect. Nevertheless, the father's struggle also has great dramatic motivation. "An agonizing struggle with a weak will (trying to reconcile with an unfriendly environment) may also contain elements of a powerful drama." (Lawson, 1989, p. 212) Unlike the fight against an external common enemy in "Sheep Without a Shepherd," some family ethics dramas focus on the fight within the family that goes wrong because each family members has emotions with different orientations, leading to a disintegration of family relations. In "All Is Well," the father is a jerk and "exploits" his daughter in an attempt to regain the respect a father deserves from his children. The father himself seeks to break his powerlessness, and his children experience anxiety regarding their expectations of their father, which jointly constitute the narrative of this type of story.

Contemporary anxiety in middle-class families is full of internal conflicts within the family unit. The psychological desires of each family member are inherently contradictory and conflict with each other. Fathers are not just individuals but encompass many roles, and ethical norms require them to exist and grow in a contradictory manner. Their social identity makes them "dominant outside the house" but not inside the house. Under the same conditions, mothers are even weaker because they can only be dominant inside the house but not outside the house. The husband and wife in "So Long, My Son" (2019) fail to achieve their goals of cooperating with each other to make up for their shortcomings because social ethical regulations do not give them a chance. They face layoffs, abortion, and the loss of their only child. Moreover, they cannot communicate effectively with each other despite wanting to and are unable to seek equality and equal abilities to spread the pressure between them. Because they do not have equal abilities, each shoulders double the responsibilities while assuming their respective full responsibilities; i.e., they worrying about the other and the other's responsibilities. Wang Liyun, the wife, wanted to have an abortion, and Liu Yaojun, the husband, wanted to stop her, but to no avail; ultimately, Liu went to the operating room hand in hand with his wife, reflecting on the "helplessness of nice people." The couple lost their fertility as well as their only child. Later, Wang Liyun attempted suicide, keeping the pain in her heart from her husband. Liu Yaojun had an affair, and after learning that his mistress was pregnant, he wanted her to have an abortion. Interestingly, during a video call in a scene near the end of the film, the couple chatted with the mistress, who immigrated to US. When the mistress introduced her child, the husband's reaction, while restrained, was interesting, and he was relieved, while being slightly disappointed, to see that the child was biracial. For Liu Yaojun, who had both the responsibilities of a husband and father, these issues cause extreme internal conflict, and he kept all of his struggles to himself, rendering him powerless. He follows the tide of the times and passively accepts fate. For fathers, the ability to communicate seems to be an impossibility in the story of modernity; they need to grow in order to acquire this ability and thus reconstruct their identity and image.

\section{The Reconstruction of the Father: Sacrifice and Sublimation}

\subsection{From Passive Compromise to Active Sacrifice}

In many films addressing the father's contemporary identity and value construction, the creators did not provide a solution for the father image dilemma. In most cases, what the father does in the films is nothing more than admit his own powerlessness and portray the passing of the old era, representing patriarchy, and the change the father can make at the narrative level is merely a dramatic "compromise." In the last scene of Ang Lee's "The Wedding Banquet" (1993), a slow motion shot shows the parents' backs, and the father, when going through security at the airport, raises both hands as if he surrenders. This scene has cultural meaning that has been frequently discussed by fans as well as scholars and practitioners in the industry; it signifies the father's own physical pain inflicted by disease, his son's life choice (gay) and the change in the family (fake marriage resulting in a pregnancy), and the father chooses to compromise. Notably, the crane shot provides a poetic representation of the image of compromise. As the father raises his hands high and finally fades out on the black screen, the audience is pulled back to reality, highlighting the sadness of the father's choice. In other words, Ang Lee, when portraying the loss of the father's power, is both relentless and sympathetic. In addition, "compromise" is a passive dramatic action, but even if passive dramatic action is not used, the narrative about the father losing momentum and the father image is reduced to a mere label, making it impossible to depict the efforts the father has made regarding his own identity. Many film and TV show creators only use the "compromise" method, albeit with sympathy. To a certain extent, the father compromises regarding the changing times and recognizes the discourse of his children, which is tantamount to giving up his own authority, representing a personal collapse. From the perspective of the children, there is an attitude of helplessness witnessing their father fading, as it is equivalent to passive "patricide."

Contemporary films have a more rational interpretation of the decline in the power of the father. On the one hand, 
film and TV show creators have deconstructed the identity of the father, which is nothing but a castle in the sky; he falls hard to the ground and a reality full of thorns. On the other hand, they, using decisive and distinctive approaches, they provide a new way to reconstruct the father image after identity deconstruction, which, although still poetic, is sacrifice. If the father in a film wants to regain the glory that belongs to him, then he must be baptized by fire. This baptism has far surpassed Ang Li's warm and nostalgic compromise in magnitude but is an adventure of near-death, a thrilling rebirth. Only after experiencing a Nirvana rebirth can the father reconstruct his fatherhood. Li Weijie, the father in "Sheep Without a Shepherd," hides the corpse to destroy evidence to protect his daughter and family, changing from a powerless nice guy to a sharp-minded, resolute, brutal perpetrator. In the past, he spoiled his daughter profusely, but as a result of his actions, he sternly "educates" her and asks her to commit perjury. Although he is very distressed and struggling, he has no regrets. The maze he faces is not solved by choosing a passive compromise. He must take action, which, step by step, makes him to commit more crimes, reaching a "point of no return." "Point of no return" is a concept of film narrative aesthetics that refers to the inability of a protagonist to go back to the previous state and thus must continue with more massively dramatic actions. In the scene in which Li Weijie watches the exhumation of the body by the police, the director chose to create mood through heavy rain. Li Weijie, who was soaked, quietly watches the exhumation of the lamb that he had used to replace the human body; although he won another round toward exoneration, he fell into a deeper abyss in because his eyes were locked on the bloody scratch on the back of the coffin lid, which provided proof that the victim had awoken and then had been suffocated alive in the coffin, a fact that was seen by Li Weijie only after the coffin was opened. Although the deceased was his enemy, he could still empathize with the victim's despair before suffocating to death. The film uses poetic treatment through a close-up crane shot in which Li Weijie, with raindrops falling on his face, looks up at the sky, looking dead, and then, the music rises, striking on the emotional cord of the viewers. Li Weijie's suffocation in the rain profoundly enacts his previous actions that pushed him into the abyss of guilt, and his internal disillusionment creates a dramatic point of no return, leading him to destruction as a father.

\subsection{Redemption and Sublimation: More Profound Absence}

The father-family conflict is manifested in the father's absence and image deconstruction and can only be dissolved through sacrifice, which is cruel and ruthless but fits the current situation of the father image. This occurs because, first, there are no other options, as mentioned above; the father has tried various methods, but his repressed powerlessness, restrained by various forces, as well as his more intense reaction to the "pain" felt in the traditional period have made him unable to find an easy solution to the problem. Second, only a transcendent outcome can secure the father-family relation at the "moment when I loved you the most." However, the cost of the sacrifice can be tremendous while the father resolves his internal conflict.

Therefore, the sublimation brought about by the sacrifice results in more absence, giving rise to a tragic cycle. One kind of sublimation is death. The prerequisite for a father's reconciliation with himself is to obtain the recognition and affirmation of others, i.e., the reconstruction of the father image is achieved through others; in other words, the absence in the past is not solved through further absence. Fathers break communication barriers and gain understanding as well as recognition as a father and self-identity, all at the expense of sacrifices, e.g., crime, devotion to family until death, apologize (i.e., fully admitting the loss of dignity as a father), etc. Absence and the loss of the father identity in a greater sense lead to a sorrowful road to redemption and tragic soul-searching. However, if nothing is broken, then nothing has to be reconstructed; through sacrifice, the father has reconstructed the value of his self-image. In "Sheep Without a Shepherd," Li Weijie, the father, turns himself in and is then taken away in a police car, during which his narration describes the events: he has always had an estranged relationship with his daughter, but he is by no means expecting that he has communicated with his daughter for the last time. The result is that family affection is present, but the father is absent. In "Detective Chinatown," the father committed a crime by following the plot described in the diary of his adopted daughter. Although he was used by his stepdaughter, he chose to confess all his crimes and committed suicide to bury the truth about his daughter through his death. The final scene before his death is rather dramatic: the wide-angle close-up shot is directly on the father's face. Because of the wide-angle lens, the father's face on the screen is distorted; additionally, the father looks at his daughter from the left side of the screen, and his face takes up approximately one-third of the screen on the left, i.e., the space in front of his face (or the space in the direction of the line of sight) is compressed, and the space behind his face is largely empty; and finally, the overexposed sun radiates directly from the top of the screen, generating a halo on the father's outline, i.e., a backlighting effect, thus imparting an unreal feeling. All these picture elements are integrated into a highly distorted and repressive image that depicts that the father is torn between psychological desires and ethical regulations, heralding the upcoming redemption. Next, without editing, with the help of the outstanding performance of Pan 
Yueming, the actor, the father shakes his head in despair and then turns abruptly, breaking the window glass with his head and throwing himself out of the building while the lens follows closely. This scene is extremely visually impactful and fully expresses the father's hopelessness leading to self-destruction and the loss of the father image. With the father's death, the truth is also concealed; the father gets what he wants through death.

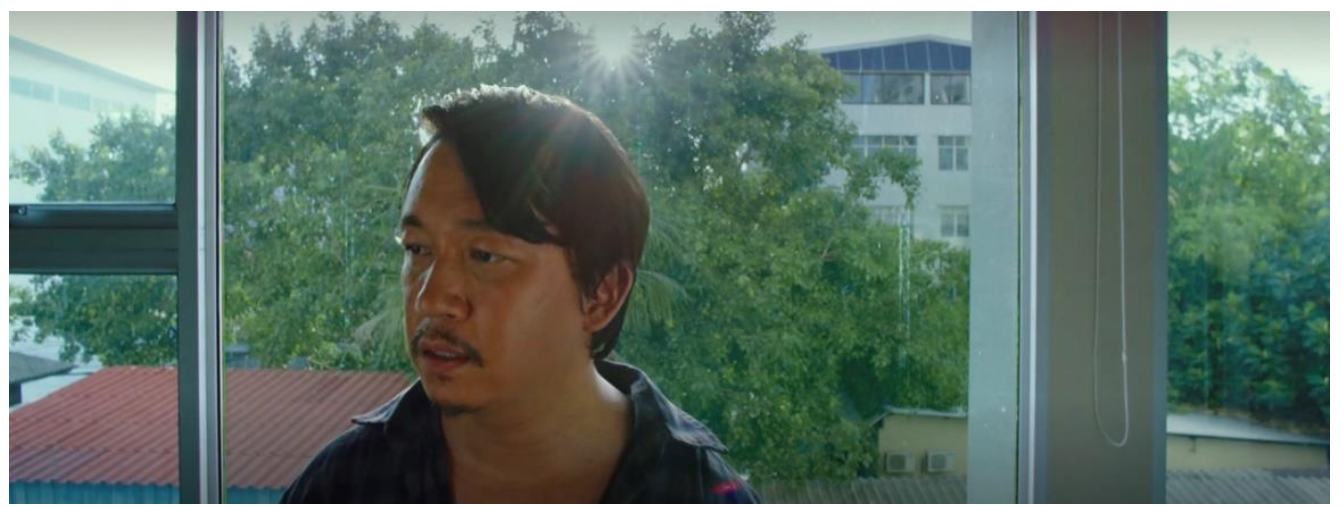

"Detective Chinatown"

Another type of sublimation is abdication, i.e., "the fading of the king." Film and TV dramas in the new era advocate the image of a gentle and good father. In other words, except for crime and death, the father claims his powerlessness, i.e., declares the limits of his power, which is essentially the implicit passing of the father. In this process, some fathers choose to apologize and give in, and others choose to irrationally ruminate on the time they had with their young kids to evoke the father/son (daughter) relationship in old days, hoping that the complicated entanglements in adult life are rewound and reset. It seems that the attachment relationship in childhood is idealized. For example, the young daughter in "Sheep Without a Shepherd" has a good relationship with the father at the beginning of the film, while the eldest daughter has entered a stage when she is unable to identify with her father, a conflict that cannot be resolved through the mother's communication and mediation because the father and mother are two completely different identities. The mother's mediation has made the children recognize more profoundly the father's "dereliction of duty" and powerlessness. In the ending scene of "Sheep Without a Shepherd," the father feels that he owes the little daughter and apologies to her, thereby declaring his incompetence while rebuilding the father-daughter relationship. "All Is Well" goes to the extreme in depicting the father-daughter relationship and accomplishes the reconstruction of the father-daughter relationship through retrospection on the time when the father was absolutely powerful and the daughter was absolutely favored. Su Daqiang, the father, suffers from Alzheimer's disease. On the way home with Su Mingyu, the daughter, the film invokes a memory and moment of empathy regarding the father-daughter relationship by the characters talking about the daughter's textbook and homework when she was little, through which grievances and estrangement between the two are dissolved. He dismisses his other responsibilities and is only focused on his young daughter's homework, which evokes the daughter's memories of that time and her relationship with her father, helping the daughter relive the past loving relationship and leading to the reconciliation between the two. These feelings are loving and portray the security and trust that a father can bring to a child through complete power when he has the absolute ability. In addition, this film also shows that when children become adults, when facing their father who is no longer strong, they can be unforgiving and intolerant because they are not sure they can escape from the status entrusted to them by their father and because of their father's inadequacy. The loss of patriarchal power is also accompanied by the growth of feminism and the strength of daughters, highlighting their pains and conflicts regarding family issues. The image of a weak father in "All Is Well" does not re-establish the authority and strength of the father image. He just relies on showing weakness to resolve conflict. His functions, whether a strong supporter or a gentle embracer, have been lost; he is now just a mediocre old man. However, under the influence of equal rights, the contemporary family does not need the father to appear as a "king". Instead, the family only seeks a peaceful and warm existence, where the father must not be "absent" but participate and be "present," including being gentle, considerate, and good at communication. Only in this way can we achieve the psychological expectation that everyone in the family is present, participates, and contributes. In other words, the family is intact and close, which seems to be a modern metaphor for "All Is Well." 


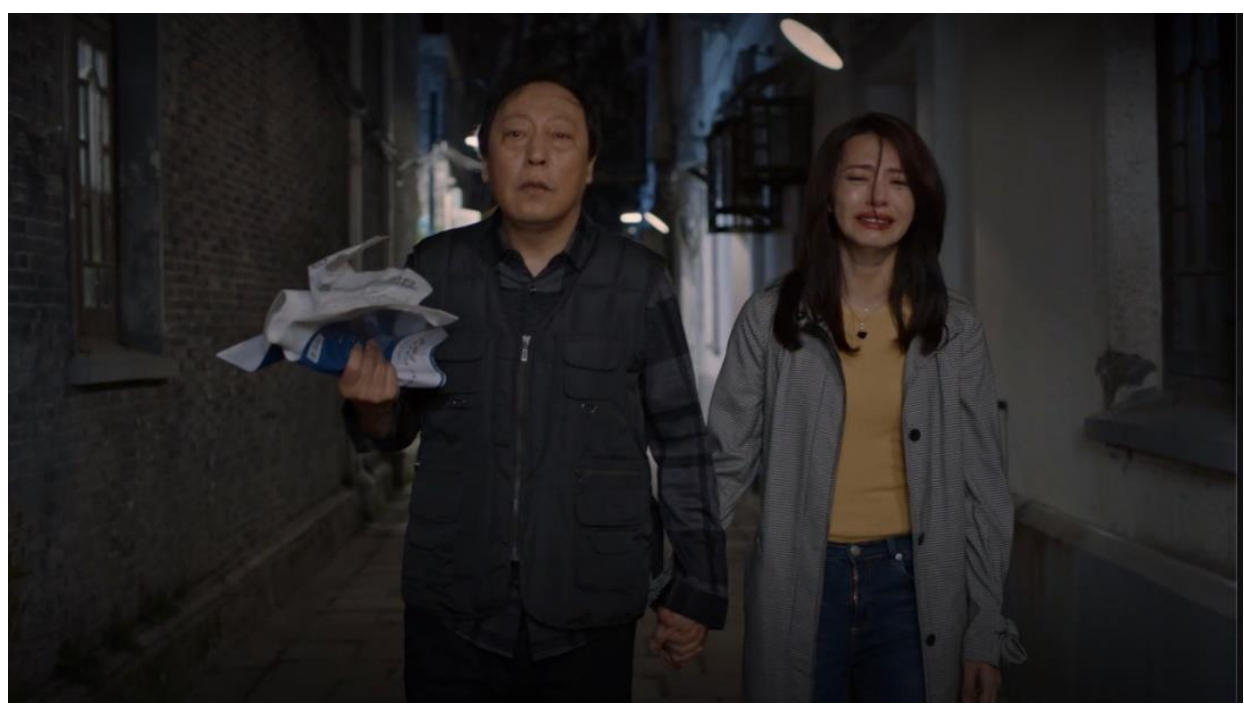

“All Is Well”

In this way, the establishment of the father image in the new era involves the establishment of a new belief. The father, with all the pride of the old tradition, resists, breaks and reconstructs a lower profile. The reconstruction of the father image is equivalent to experiencing the pain of the phoenix in Nirvana, through which rebirth, sublimation and liberation are achieved. Fathers need to break the constraints of old traditions and complete a sacrificial act of rejecting the old system to resolve conflicts with the next generation and rise from the ashes to build a new, gentle, warm, peaceful, and ordinary father figure that actively participates in family activities to regain a new voice in contemporary society.

\section{Conclusion}

The father image in contemporary Chinese films is a metaphor of the era for family relations and social identity in the new century. Under the dual effect of the influence of Chinese traditional culture and the penetration of modern thoughts, the identity of the father image has produced many inherent conflicts. Fathers have lost their original power outside the family while being deprived of rights within the family, with the father image becoming an empty concept. The old era that attests their identity has long gone, while the new age has abandoned them. Their power is useless, and their relations with the family have been minimized; therefore, they have developed a deep sense of powerlessness. Contemporary film and TV dramas have accurately grasped the abstract concept of the absence of the father image, showing the loss of discourse and disintegration of the father image in a deconstructive way while, not without sympathy, empowering fathers with the rights to resist. However, the road of a father's resistance is densely covered with thorns. Fathers are powerless in fighting against reality, i.e., the old identity of the father image; therefore, they become negative and even self-destructive, resulting in the reconstruction of the father identity. This reconstruction occurs through Film and TV creators' rational choices and artistic poetic expression, in which fathers, through sacrifices, reconcile with the family, generate a new self-identity, and reconstruct the father figure. Although cruel, it is tragic and forceful. This process from identity deconstruction to reconstruction is an important cultural theme in contemporary Chinese film and TV dramas, as well as a modern inheritance of traditional culture, which deserves more close attention and exploration of scholars and industry practitioners.

\section{References}

Lawson, J. H. (1989). Theory and technique of playwriting (A Dramabook) (M. J. Shao \& Q. Zhou, trans.). Beijing: China Film Publishing House.

Li, D. X. (2002). The father image in early Chinese films and its cultural meanings, Film Art, (6), 106-107.

Yu, X. (2009). The Image of Father of Chinese Mainland Movies: The father's return: Analysis on the father image of the mainland Chinese films. Film Studies in China Contemporary Cinema, (11), 123-126.

Zoja, L. (2015). The Father (M. Zhang, J. X. Wang \& W. W. Mi, trans.). Beijing: World Book Publishing Company Beijing Office. 


\section{Notes}

Story arc refers to the overall dramatic action of the narrative. According to Lawson, an American playwright, "The movement of drama is driven by a series of changes in the state of balance. Any change in the state of balance constitutes an action. A drama is an action system." [US] John Howard Lawson: "Theory and technique of playwriting (A Dramabook).” translated by Shao Mujun and Qi Zhou, China Film Publishing House, 1989, p. 214.

\section{Copyrights}

Copyright for this article is retained by the author(s), with first publication rights granted to the journal.

This is an open-access article distributed under the terms and conditions of the Creative Commons Attribution license (http://creativecommons.org/licenses/by/4.0/). 